ECCOMAS

Proceedia
COMPDYN 2021

$8^{\text {th }}$ ECCOMAS Thematic Conference on Computational Methods in Structural Dynamics and Earthquake Engineering M. Papadrakakis, M. Fragiadakis (eds.) Streamed from Athens, Greece, 28 - 30 June 2021

\title{
INVESTIGATING GROUND-MOTION DURATION EFFECTS ON BUILDING PORTFOLIO LOSS ESTIMATES
}

\author{
Kenneth Otárola-Madrigal ${ }^{1}$, Roberto Gentile ${ }^{2}$, Luis Sousa ${ }^{3}$, and Carmine Galasso ${ }^{1,2}$ \\ ${ }^{1}$ Scuola Universitaria Superiore (IUSS) Pavia, Pavia, Italy \\ e-mail: kenneth.otarola@iusspavia.it \\ ${ }^{2}$ University College London, London, United Kingdom \\ e-mail: \{r.gentile, c.galasso\}@ucl.ac.uk \\ ${ }^{3}$ AIR worldwide London Ltd., London, United Kingdom \\ e-mail: LSousa@air-worldwide.com
}

\begin{abstract}
Earthquake-induced ground-motion duration can be an important factor to consider when assessing ground-motion damage potential, as evidenced by recent earthquake events worldwide. In current practice, duration is commonly relegated to implicit, qualitative considerations. This study introduces a framework to explicitly quantify the influence of duration on building portfolio direct economic losses. To this end, a simulation-based probabilistic risk modelling framework is developed for different synthetic building portfolios impacted by a case-study seismic source. Two building typologies, representative of distinct vulnerability classes in southern Europe, are considered. A simulation-based probabilistic seismic hazard analysis is performed, explicitly simulating duration jointly with spectral-shape-related intensity measures. Sets of long and one-to-one spectrally-equivalent short duration ground-motion records are selected and then used jointly to perform nonlinear dynamic analysis and derive fragility models for each considered building typology. Fragility relationships are derived by using average spectral acceleration as the primary intensity measure and: 1) maximum inter-storey drift ratio as a demand parameter, indirectly accounting for ground-motion duration (through the adopted nonlinear modelling strategy); 2) maximum inter-storey drift ratio as demand parameter, explicitly considering duration as an intensity measure together with spectral shape, in a vectorvalued format. For each case, vulnerability models are developed by combining the fragility relationships with a building-level damage-to-loss model. The portfolio expected annual losses estimated using the described vulnerability models are critically compared and discussed. Depending on the location/portfolio, the impact of ground-motion duration can be significant, and the proposed approaches allow an analyst to account for it in a practical way.
\end{abstract}

Keywords: Ground-motion duration; nonlinear dynamic analysis; maximum inter-storey drift ratio; building portfolio loss. 


\section{INTRODUCTION}

Earthquake events have been responsible for devastating human, environmental and economic losses in modern societies over the years. Portfolio risk assessment represents the first step towards developing risk reduction and resilience-enhancing strategies for earthquakeprone regions. Earthquake risk assessment generally requires three main modelling components: a probabilistic seismic hazard model (simulating representative earthquake scenarios in time and space and assessing the resulting ground-shaking intensity across a geographical area at risk); a comprehensive exposure dataset (containing details on the location and characteristics of the assets at risk in the geographic area of concern); and a set of (physical) vulnerability models for those exposed assets/asset types (e.g., [1]), quantifying the susceptibility to damage, or other forms of loss (e.g., downtime and casualties), of structures and their contents because of the hazard impact. This latter component plays a significant role in earthquake risk modelling/risk reduction since reducing physical vulnerability leads to a direct decrease in the associated seismic risk. Therefore, understanding and quantifying the various earthquake-induced ground-motion characteristics driving seismic vulnerability becomes crucial.

Current seismic design and risk assessment procedures commonly characterise ground motions in terms of amplitude and frequency-related parameters (e.g., spectral ordinates) without explicitly considering ground-motion duration. Large-magnitude events worldwide, often resulting in long-duration ground motions [2] (e.g., the 2010 Maule Chile earthquake, moment magnitude, $\mathrm{M}_{\mathrm{w}}$ 8.8; the 2011 Tohoku Japan, $\mathrm{M}_{\mathrm{w}}$ 9.0) caused billions of dollars in losses, emphasising the need to account for ground-motion duration in practical earthquake risk assessment exercises. The importance (and influence) of amplitude and frequency-related parameters on ground-motion-induced damage and losses have been comprehensively investigated and quantified. However, a consensus has not been reached yet concerning the impact of groundmotion duration on structural response, building performance, and resulting damage/losses.

The main difficulty in quantifying the effect of duration on seismic response of structures is related to the challenging task of decoupling this specific effect from the impact of other ground-motion characteristics. Duration is considered an essential factor in assessing a groundmotion damage potential, but its significance remains unclear, partly because of the somehow contradictory and inconclusive results of some past studies (e.g., [3]). Such conflicting findings from prior studies mainly result from the adopted definition of strong-motion duration, the structural demand parameters utilised to quantify damage, and the inadequacy of the numerical models in capturing the stiffness and strength cyclic and in-cycle deterioration of different structural systems.

Some studies (e.g., [4]) have demonstrated that while duration has no significant effect on peak-based demand parameters (e.g., maximum inter-story drift ratio, MIDR), it can have a significant effect on cumulative demand parameters (e.g., dissipated hysteretic energy, EH). On the other hand, studies that utilised analytical models accounting for stiffness and strength cyclic and in-cycle deterioration (e.g., [5]) demonstrated that long-duration ground motions impact cumulative damage and collapse capacities. However, the degree of importance of duration effects may vary depending on the structural system under consideration.

Significant advances on the topic have been recently made due to the increasing availability of reliable long-duration ground-motion records and improved deteriorating nonlinear structural models incorporating the destabilising P- $\Delta$ effects (e.g., [2], [6]). These studies focused primarily on the influence of ground-motion duration on structural collapse capacity and structural collapse risk, using novel ground-motion selection procedures to isolate the effects of duration from the response spectral shape by using "spectrally equivalent" long- and shortduration ground-motion records. This approach assumes a weak correlation between spectral 
shape (i.e., spectral acceleration ordinates) and duration (i.e., significant duration), which may not be a realistic assumption in some cases.

Literature describing how duration affects structural fragility for different damage states and their evaluation is not widely available. In [7], this modelling challenge was tackled using two different approaches. In the first approach, the effect of duration was decoupled from the effects of amplitude and spectral shape by assembling sets of spectrally equivalent long- and shortduration ground motions. Those sets of records were employed in comparative incremental dynamic analyses to derive fragility and vulnerability models using realistic SDoF deteriorating nonlinear models. Formal hypothesis testing was also employed to assess the analyses results' statistical significance quantitatively. The second approach employed the generalised conditional intensity measure (GCIM) method to select hazard-consistent ground motions. Those ground motions were used as an input to multiple stripe analyses using realistic MDoF deteriorating nonlinear models. The impact of duration was investigated by variance analysis and in terms of vector-valued fragility and vulnerability models.

Most of the existing studies, as noticed, focus on structural response/building performance assessment, and very few on building-specific loss assessment (e.g., [8]). To the best of the authors' knowledge, no past studies investigated the effect of ground-motion duration on building-portfolio direct economic losses. Accurately quantifying the potential impact of groundmotion duration on portfolios of buildings located in seismically prone regions, as proposed in this study, can be of interest to different stakeholders (e.g., property owners, (re)-insurers).

The study begins with an overview of the simulation-based risk assessment framework employed in the study. The proposed methodology relies on probabilistic seismic hazard analysis (PSHA), incremental dynamic analysis-based [9] fragility derivation (scalar and vector-valued models are considered [10]), and simulation-based loss estimation. The approach is applied to two synthetic portfolios of the same size, located in the fault-parallel orientation with respect to a case-study strike-slip fault. Different structural types are considered for each portfolio, including gravity-designed and seismically-designed reinforced concrete (RC) frames. The results are discussed considering the effects of ground-motion duration on the median loss and expected annual loss (EAL) of the considered location/portfolios at different distances from the case-study fault.

\section{SIMULATION-BASED SEISMIC LOSS ASSESSMENT}

The implemented simulation-based risk assessment framework [11] is schematically illustrated in Figure 1. Sections 2.1 to 2.4 describe the relevant hazard, exposure and vulnerability framework components and the associated direct loss estimations within this framework.

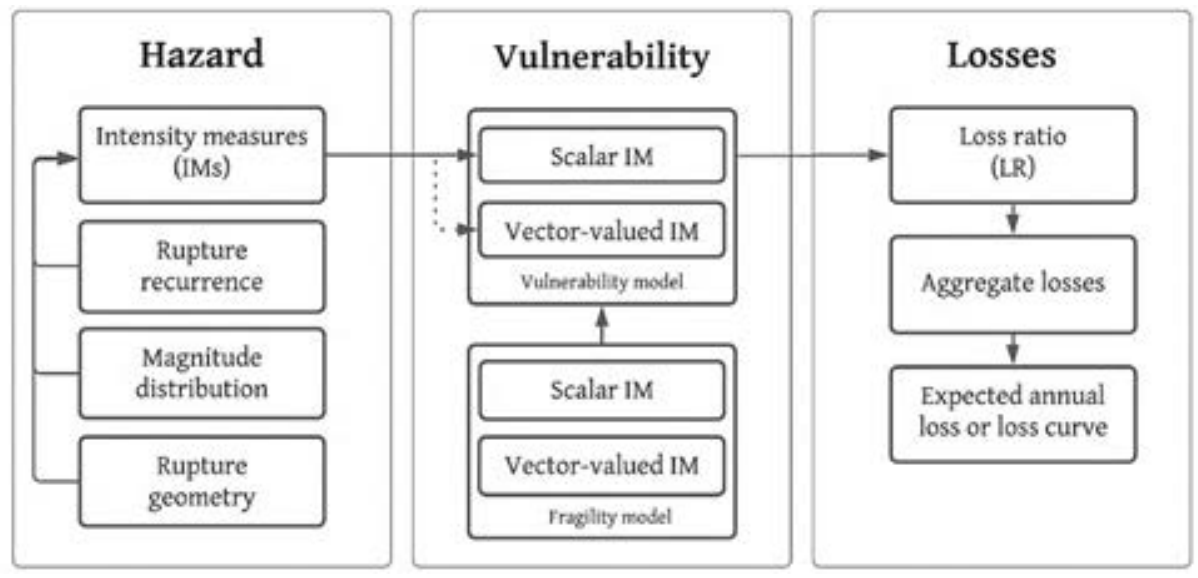

Figure 1: Simulation-based risk assessment framework. 
Event-based PSHA [12] is used to simulate 1) seismicity in the considered region as described by a source model; and 2) the resulting ground shaking at the considered set of locations by using a ground-motion model (GMM). Specifically, a stochastic event set (i.e., a stochastic catalogue) is generated for a given time span, chosen based on the minimum rate of exceedance of interest. The number of earthquake occurrences within this period is simulated by sampling the probability distribution for the considered source model's rupture occurrence. The geometry (constraining the earthquake rupture location) and the magnitude-frequency distribution (defining the average annual occurrence rate over a magnitude range) describe the considered source models. For each event in the catalogue, the corresponding magnitude is first simulated from the magnitude-frequency distribution. Next, following the Joyner-Boore source-to-site distance definition, the distance to the rupture for each location of interest is assigned (shallow rupture with a dip angle of $90^{\circ}$ and strike of $0^{\circ}$ ). Then, ground-motion intensity measures (IMs) of interest are sampled from the probability distributions defined by the GMM, accounting for cross-IM correlation. The set of simulated ground-shaking IMs at the various locations forms a ground-motion field; various ground-motion fields are generated to capture the aleatory variability (both inter- and intra-event) in the GMM.

Given a suite of site-independent ground-motion records with similar spectral shape but different durations, fragility, and vulnerability models (scalar and vector-valued) are derived for each considered building type within the considered portfolios. For each location, building type and simulated IMs, the loss ratio is calculated using the appropriate vulnerability model accounting indirectly or directly for ground-motion duration. The total portfolio loss is calculated by summation over all the building locations in each simulation.

Loss exceedance curves (mean annual frequency, MAF, of exceedance vs loss ratio/loss value) for specific buildings/locations and the entire portfolio can be estimated using the obtained ground-motion fields, leading to lists of events and corresponding loss ratios/loss values. The lists are sorted from the highest loss ratio/loss value to the lowest. The rate of exceedance of each loss ratio/loss value is computed by dividing the number of exceedances of that loss ratio by the length of the event set (eventually multiplied by the number of stochastic event sets, if more than one set are generated). By assuming a Poisson distribution of the occurrence model, the probability of exceedance of each loss ratio/loss value can also be estimated. The portfolio EAL can be calculated by averaging over all the simulations and events.

\subsection{Hazard}

A Poisson model is used to simulate the events' earthquake occurrence on the considered fault. The characteristic earthquake-recurrence model by [13] is adopted to simulate each event associated $\mathrm{M}_{\mathrm{w}}$. It consists of a log-linear recurrence relationship (i.e., frequency of occurrence vs $\mathrm{M}_{\mathrm{w}}$ ) for moderate (non-characteristic) events and a constant probability branch of occurrence for large (characteristic) events. This model is based on observations that during repeated ruptures occurring on the same fault (or fault system), some characteristics, such as fault geometry, source mechanism, and seismic moment, remain approximately constant over a significant time. The magnitude-dependent length of the rupture is obtained from the equations proposed by [13]. The Joyner-Boore distance is used to define the source-to-site distances for the set of locations of interest.

The amplitude- and duration-based ground-motion IMs (i.e., average spectral acceleration, AvgSa and significant duration, Ds5-95) are simulated for each seismic event in the stochastic catalogue using the approach presented in [14] for correlated random realisations from a multivariate lognormal distribution (including cross-IM correlation). The AvgSa and Ds5-95 realisations are obtained using appropriate GMMs (i.e., [15]; [16]) and empirical correlation models (i.e., [17]; [18]) for spectral acceleration (Sa) ordinates (to estimate AvgSa) and Ds5-95. It is 
worth noting that different models should be considered and combined in a logic tree to consider the epistemic uncertainties included in the framework. Nevertheless, one set of models is utilised since the study focuses on introducing the proposed simulation-based loss estimation framework and relative loss results.

It is also worth mentioning that only the combined (intra- and inter-event) GMM uncertainty is considered in this study for simplicity (and computational efficiency), with no consideration of ground-motion spatial correlation (among the locations of the portfolio). Yet, a full correlation for the buildings pertaining to one single site is implicitly assumed since ground shaking is herein simulated for each location (rather than for each building). Many studies (e.g., [19]) have shown that the spatial correlation in ground-motion IMs has important implications on probabilistic seismic hazard and loss estimates of spatially distributed systems (e.g., building portfolios). Inclusion of spatial correlation of IMs into the seismic risk analysis may often result in the likelihood of observing more significant (and in some instances smaller) losses for a portfolio distributed over a typical city-scale when compared against simulations in which this correlation is neglected. Therefore, in practice, the spatial correlation must be included. This is a future development of the current study.

\subsection{Exposure}

Various building portfolios located nearby a causative fault are considered. Each portfolio consists of several equally spaced locations (i.e., sites). In each location, a group of buildings of different typologies (or taxonomy) is collocated (i.e., the exposure is "lumped" at the considered sites). Each portfolio is also moved (utilising $3 \mathrm{~km}$ intervals) horizontally through the entire region (perpendicularly to the fault) to assess the ground-motion duration influence on the loss curves/EAL with respect to the distance from the fault.

\subsection{Vulnerability}

Fragility relationships are derived by using incremental dynamic analysis (IDA) with AvgSa as the primary IM and: 1) MIDR as a demand parameter, indirectly accounting for duration, through an advanced nonlinear structural model; 2) MIDR as demand parameter, explicitly considering duration as an IM together with spectral shape, in a vector-valued format. For each case, vulnerability models are developed by combining the fragility relationships with a building-level damage-to-loss model. It is worth noting that MIDR can account indirectly for the duration since the hysteretic models utilised here ([20]; [21]) accounts for the cyclic and incycle strength and stiffness deterioration of the structural components based on the EH of the components, following the deterioration rule developed by [22].

When using a scalar IM (i.e., AvgSa), the probability of reaching or exceeding a damage state (DS) at a given IM level can be estimated as the fraction of records for which this DS occurs at a level lower than the defined IM. This probability can be calculated as shown in equation 1, assuming a lognormal distribution.

$$
P\left(D S \geq d s_{i} \mid I M\right)=\Phi\left[\frac{\ln (I M / \mu)}{\beta}\right]
$$

The fragility relationship mean, $\ln (\mu)$, and standard deviation, $\beta$ (i.e., dispersion), are computed with equations 2 and 3 (i.e., by using the method of moments estimator as described in [23]). In these equations, $n$ is the number of considered ground-motions; $I M_{i}$ is the intensity measure value associated with the onset of a DS for the $\mathrm{i}^{\text {th }}$ ground motion. $\Phi$ is the CDF of the standard Gaussian distribution. 


$$
\begin{gathered}
\ln (\mu)=\frac{1}{n} \sum_{i=1}^{n} \ln \left(I M_{i}\right) \\
\beta=\sqrt{\frac{1}{n-1} \sum_{i=1}^{n}\left[\ln \left(\frac{I M_{i}}{\mu}\right)\right]^{2}}
\end{gathered}
$$

When using a vector-valued IM (i.e., [AvgSa, Ds5-95] in this study), although only a single IM parameter is scaled during IDA, it is still possible to determine the effects of other IMs. In such context, $\mathrm{IM}_{2}$ (i.e., Ds5-95) can explain part of the variation of the associated $\mathrm{IM}_{1}$ (i.e., AvgSa). Therefore, the probability of exceeding the $\mathrm{IM}_{1}$ associated with the target EDP (i.e., MIDR) level can be expressed in terms of a conditional distribution of $\mathrm{IM}_{1}$ given $\mathrm{IM}_{2}$. Linear regression is used to find the conditional mean of $\ln I M_{1}$ given $\ln I M_{2}$ as shown in equation 4 . $\beta_{0}$ and $\beta_{1}$ are coefficients estimated from linear regression using the data points. The conditional standard deviation $\left(\sigma_{\ln I M_{1} \mid l n I M_{2}=\operatorname{lnim}_{2}}\right)$ of $\ln I M_{1}$ given $\ln I M_{2}$ is estimated computing the standard deviation of the regression residuals (root mean squared error).

$$
\mu_{\ln I M_{1} \mid \ln I M_{2}=\operatorname{lnim}_{2}}=\beta_{0}+\beta_{1} \operatorname{lnI} M_{2}
$$

If the conditional distribution of $\ln I M_{1}$ given $\ln I M_{2}$ is assumed to be Gaussian, the conditional mean and standard deviation calculated completely define the conditional distribution of $\ln I M_{1}$ associated with reaching an EDP level. Thus, the CDF of this conditional distribution can be estimated as in equation 5, where $\Phi$ is the CDF of the standard Gaussian distribution.

$$
P\left(I M_{1}<i m_{1} \mid D S=d s_{i}, I M_{2}=i m_{2}\right)=\Phi\left(\frac{\operatorname{lnim}_{1}-\mu_{\operatorname{lnI} M_{1} \mid \operatorname{lnI} M_{2}=\operatorname{lnim}_{2}}}{\sigma_{\operatorname{lnIM}_{1} \mid \operatorname{lnIM}_{2}=\operatorname{lnim}_{2}}}\right)
$$

Damage loss ratios (DLRs) are usually estimated empirically through post-earthquake reconnaissance data or employing expert judgment. These ratios are site-specific and buildingtype-specific and must be carefully selected while developing vulnerability models (e.g., [24]). For this study, the DLRs suggested by [25] are considered. The definition of the damage loss ratios is shown in Table 1 (from no damage, DS0 to collapse, DS5).

\begin{tabular}{ccccccc}
\hline DSs & DS0 & DS1 & DS2 & DS3 & DS4 & DS5 \\
\hline DLRs & 0.00 & 0.01 & 0.10 & 0.35 & 0.75 & 1.00 \\
\hline
\end{tabular}

Table 1: Definition of damage-to-loss ratios.

Vulnerability models are expressed here in terms of loss ratio (LR), i.e., the repair-to-replacement cost ratio of the building conditional on the level of ground-shaking IM. Such functions are derived according to equation 6 , using the law of total expectation. $D L R_{i}$ is the damage-to-loss ratio for the $\mathrm{i}^{\text {th }}$ damage level DS, whilst $P\left(D S=d s_{i} \mid I M\right)$ is the probability that the DS is equal to dsi (probability of being in each damage state). It is worth noting that IM here could be a single IM composed only by AvgSa, or a vector-valued IM including AvgSa and Ds5-95 as derived above, resulting in vector-valued vulnerability relationships.

$$
L R(I M)=\sum_{i} D L R_{i} P\left(D S=d s_{i} \mid I M\right)
$$




\subsection{Loss assessment}

For each event and IM simulation (i.e., ground-motion field), the mean LR is computed using the pertinent vulnerability models. This process is replicated for each location within the portfolio, and each considered building typology, $t$. According to [11], for each computed LR, the ground-up loss at each of the $n_{l o c}$ locations is calculated through equation 7 , assuming $N_{b, t}$ buildings of typology $t$ for which the replacement cost is equal to $C R_{b, t}$. Such cost (cost of structural/non-structural component and contents inclusive) is often provided in the exposure model. The loss ratio for every location for a given IM is calculated with equation 8 .

$$
\begin{gathered}
L_{l o c}(I M)=\sum_{t} L R_{b, t}(I M) N_{b, t} C R_{b, t} \\
L R_{l o c}(I M)=\frac{L_{l o c}(I M)}{C R_{l o c}}=\frac{\sum_{t} L R_{b, t}(I M) N_{b, t} C R_{b, t}}{\sum_{t} N_{b, t} C R_{b, t}}
\end{gathered}
$$

Assuming that $C R_{b, t}=C R$ for each $b$, the equation 8 is simplified into equation 9, in which $n_{b, t}=N_{b, t} / \sum_{t} N_{b, t}$ is the proportion of building typologies, $t$. Considering that the distribution of buildings $n_{b}$ is uniform through the portfolio, the portfolio LR is calculated as the mean of loss ratios per location (equation 10). Given such assumptions, there is no need to assume any $C R$ nor the number of buildings at the given location for each building typology without jeopardising the result generality. The outcome is expressed in terms of loss exceedance curves and EAL, representing the expected loss per year (statistical mean loss) and is used as an estimate of the annual insurance premiums to cover the peril [26]. The EAL is calculated, averaging the portfolio LR for each event and simulation in the stochastic catalogue.

$$
\begin{gathered}
L R_{l o c}(I M)=\frac{\sum_{t} L R_{b, t}(I M) N_{b, t}}{\sum_{t} N_{b, t}}=\sum_{t} L R_{b, t}(I M) n_{b, t} \\
L_{l o c}(I M)=\frac{\sum_{l o c} L_{l o c}}{C R_{\text {port }}}=\frac{\sum_{l o c} L R_{l o c} C R_{l o c}}{\sum_{l o c} C R_{l o c}}=\frac{\sum_{l o c} L R_{l o c}}{n_{l o c}}
\end{gathered}
$$

\section{ILLUSTRATIVE APPLICATION}

\subsection{Considered ground-motion records}

The ground-motion dataset employed in this study is a subset of the Pacific Earthquake Engineering Research Center NGA-West2 database [27]. Sets of long and one-to-one spectrallyequivalent short duration ground-motion records are used herein as described by [2]. Firstly, a set of long duration records is selected considering all the records within the NGA-West2 database complying with the following criteria: a) $10 \mathrm{~km} \leq \mathrm{R}_{\text {rup }} \leq 250 \mathrm{~km}$; b) $30 \mathrm{~s} \leq \mathrm{Ds} 5-95 \leq 60 \mathrm{~s}$; c) a minimum $\mathrm{M}_{\mathrm{w}}=5 ; \mathrm{d}$ ) a minimum $\mathrm{PGA}=0.1 \mathrm{~g}$; and e) a minimum $\mathrm{PGV}=10 \mathrm{~cm} / \mathrm{s}$. R rup is the minimum distance to the rupture surface; $\mathrm{M}_{\mathrm{w}}$ is the moment magnitude of an earthquake; and PGA and PGV are the peak ground acceleration and peak ground velocity of the ground motions, respectively. Secondly, the companion set of short-duration records is assembled, selecting a corresponding record with Ds5-95 smaller than $25 \mathrm{~s}$ for each long record, and closely matching the response spectrum of the long-duration record. The ones with the lowest sum of squared errors (SSE vary from 0.19 up to 0.95 ) are chosen from all the candidate short duration records. Finally, 200 ground-motion records are utilised (see Figure 2). The selected sets of 
short- and long-duration records are finally combined together to cover a wide range of relevant IM values in performing nonlinear dynamic analysis of the considered archetype frames.

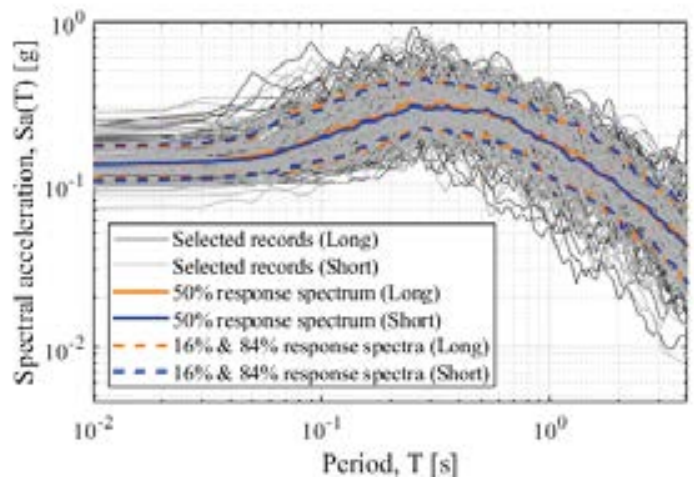

a) Ground-motion response spectra

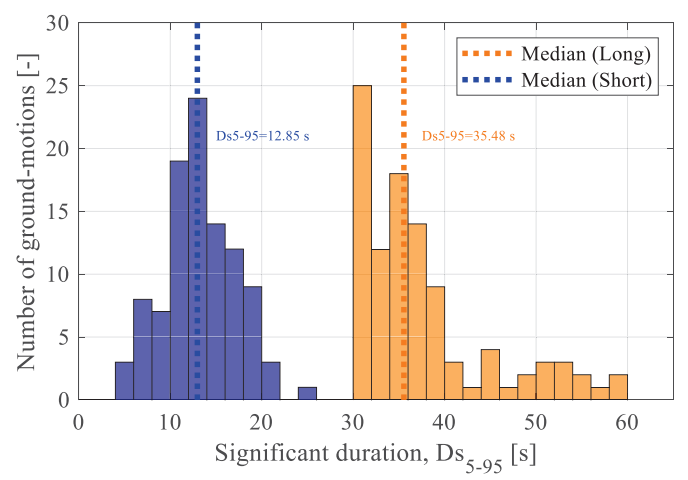

b) Ground-motion significant durations

Figure 2: Selected ground-motion records.

\subsection{Considered building typologies}

The considered mid-rise reinforced concrete $(\mathrm{RC})$ building models represent distinct vulnerability classes in southern Europe. The total building height is equal to $13.5 \mathrm{~m}$, with a first storey of $4.5 \mathrm{~m}$, upper storeys of $3 \mathrm{~m}$ and a bay width of $4.5 \mathrm{~m}$ in both directions [28]. Two moment-resisting frames are considered using the same geometry. The first case-study frame, termed as special-code frame, is designed and detailed according to the seismic provisions of the EC8 for high ductility class [29]. These provisions include capacity design, various requirements in terms of cross-sectional dimensions and seismic detailing to ensure a ductile global performance and preventing the formation of localized brittle failure modes. The other frame, termed as pre-code frame, is designed for gravity loads only as per the Royal Decree n. 2239 of 1939 [30] that regulated the structural design in Italy until 1974. Therefore, this frame does not conform to modern seismic requirements. A non-ductile behaviour characterizes it due to the lack of strength hierarchy rules, sufficient longitudinal reinforcement, poor confinement, and susceptibility to develop brittle failure mechanisms (see [31] for more details). According to this distinction, the two case-study frames include a pre-code bare (PB) frame and a specialcode bare (SB) frame. Figure 3a depicts the elevation layout of these frames.

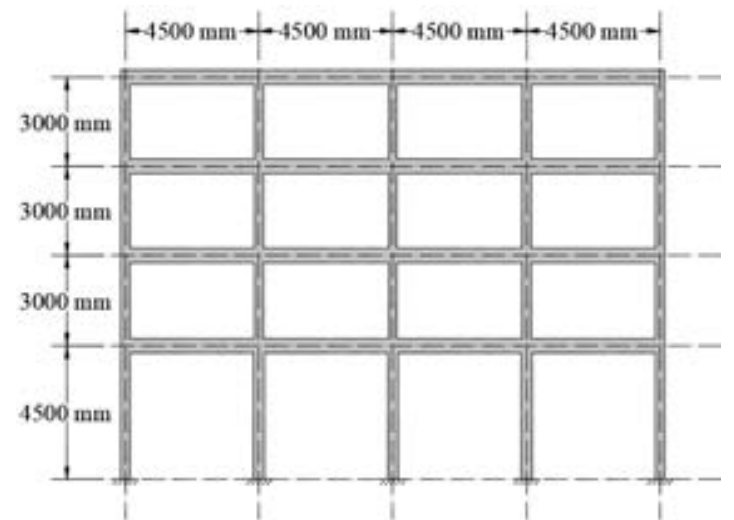

a) Elevation geometric layout

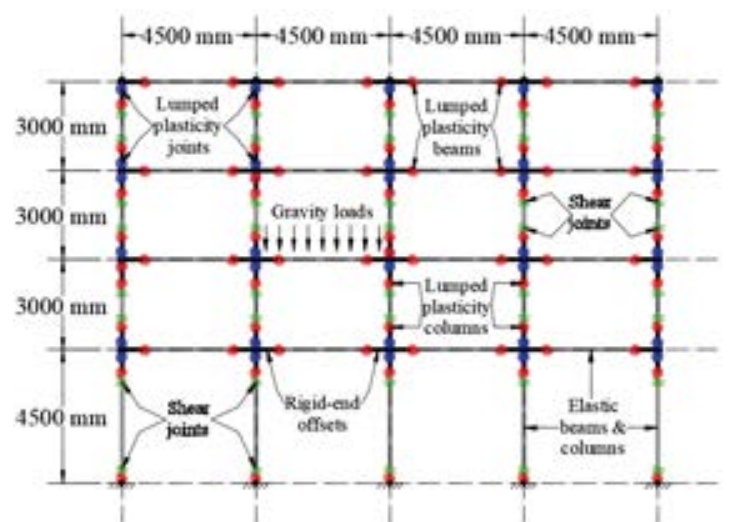

b) Analytical-numerical model

Figure 3: Geometric elevation definition and modelling strategy of the buildings.

Regarding the materials used for each building, their mean mechanical properties, such as the concrete compressive strength and the rebar steel yield strength, represent those typically adopted in southern Europe. For the pre-code frame, mean concrete mechanical properties are 
obtained from [32] and [33], while for the special-code frame are obtained from [34] and based on the current practice. The described material properties are summarised in Table 2.

\begin{tabular}{lcccc}
\hline Parameter & Symbol & Units & Pre-code & Special-code \\
\hline Compressive strength of concrete & $\mathrm{f}_{\mathrm{cm}}$ & $\mathrm{MPa}$ & 19 & 37 \\
Modulus of elasticity of concrete & $\mathrm{E}_{\mathrm{c}}$ & $\mathrm{MPa}$ & 26670 & 32600 \\
Yield strength of rebar steel & $\mathrm{f}_{\mathrm{ym}}$ & $\mathrm{MPa}$ & 360 & 490 \\
Modulus of elasticity of rebar steel & $\mathrm{E}_{\mathrm{s}}$ & $\mathrm{MPa}$ & 200000 & 200000 \\
\hline
\end{tabular}

Table 2: Properties of the reinforced concrete.

The case-study structure response is simulated by two-dimensional numerical models adopting the finite element software OpenSees [35], as shown in Figure 3b. For all the case studies, gravity loads are uniformly distributed on the beams and masses concentrated at master joints on different floors. Besides, elastic damping is modelled through the Rayleigh model [36], using a 5\% viscous damping ratio on the first two vibration modes. Moreover, geometric nonlinearities are included to account for $\mathrm{P}-\Delta$ effects.

A lumped plasticity approach is utilised to model both beams' and columns' nonlinear behaviour using zero-length rotational springs. Beam-column end-offsets and floor diaphragms are modelled as rigid. The moment-rotation constitutive relationship for beam and columns is consistent with the models developed by [37]. The peak-oriented hysteretic model (as defined by [20] and further refined by [21]) describes the strength and stiffness deterioration (cyclic and in-cycle). For pre-code frames only, nonlinear shear springs are added in series to the rotational ones to account for brittle mechanisms consistent with the model developed by [38].

Structure-specific MIDR thresholds for five DSs are calibrated via pushover analyses by reviewing multiple measurable criteria according to [31], which are based on [39] and [29]. The pushover load patterns are defined according to the first mode shape, as indicated in [29]. The selected DSs thresholds are shown in Table 3. Some relevant information on the case-study buildings' dynamic behaviour, such as the first- and second-mode vibration periods and the corresponding mass participation ratios, is summarised in Table 4.

\begin{tabular}{cccccc}
\hline Case-study & \multicolumn{5}{c}{ Damage states } \\
\cline { 2 - 6 } frames & DS1 & DS2 & DS3 & DS4 & DS5 \\
\hline PB & $0.15 \%$ & $0.25 \%$ & $1.40 \%$ & $2.00 \%$ & $3.50 \%$ \\
SB & $0.17 \%$ & $0.40 \%$ & $2.70 \%$ & $3.85 \%$ & $8.00 \%$ \\
\hline
\end{tabular}

Table 3: Definition of damage state thresholds for MIDR.

\begin{tabular}{ccc}
\hline Parameter & PB frame & SB frame \\
\hline Fundamental structural period & $\mathrm{T}_{1}=0.83 \mathrm{~s} ; \mathrm{T}_{2}=0.25 \mathrm{~s}$ & $\mathrm{~T}_{1}=0.50 \mathrm{~s} ; \mathrm{T}_{2}=0.15 \mathrm{~s}$ \\
Mass participation ratio & $94.50 \%$ & $91.96 \%$ \\
\hline
\end{tabular}

Table 4: Fundamental structural periods and mass participation ratios.

\subsection{Considered building portfolios}

Two synthetic building portfolios are considered in this study. As shown in Figure 4, a faultparallel "zone" is first defined as located next to a case-study strike-slip fault. The zone is defined so that the closest sites are located at $5 \mathrm{~km}$ minimum from the fault; each portfolio is moved perpendicularly from the fault to assess the effects of distance on ground-motion duration (and, consequently, losses). Within the considered zone, the centroid of each location in the portfolio is distributed on a uniform lattice approximately $3 \mathrm{~km}$-spaced. Thus, a $9 \mathrm{~km}^{2}$ area 
pertains to each location. Such choice allows attaining a balance between computational burden and accuracy in the outcomes [11].

A $36 \mathrm{~km} \mathrm{x} 36 \mathrm{~km}$ base portfolio is used as a standard size and is considered representative of a small region. Two different exposure configurations are also considered, considering that each location has the same building composition. These configurations involve a single building typology (i.e., PB or SB) only.

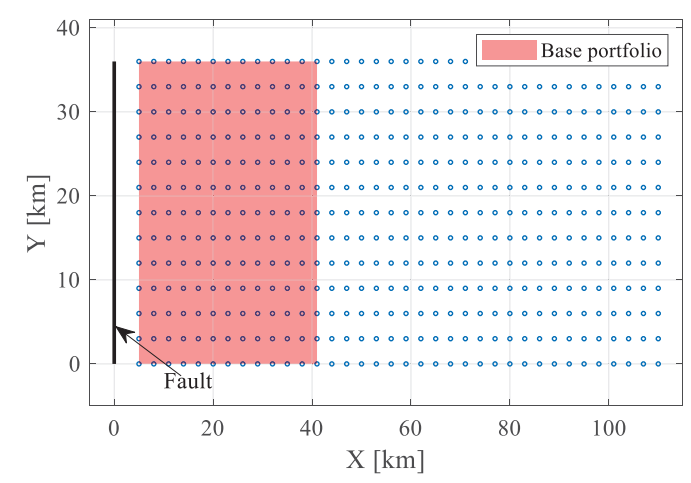

Figure 4: Geometric definition of building portfolios.

\subsection{Considerations for the stochastic catalogue}

The considered case-study strike-slip fault is defined by the characteristic earthquake-recurrence model shown in [40]. The necessary parameters for this model are assumed as follows: $\mathrm{m}_{\mathrm{c}}=6.4$ (characteristic earthquake magnitude); $\mathrm{b}=1$ ( $b$-value of the Gutenberg-Richter law); $\mathrm{M}_{\min }=5 ; \mathrm{M}_{\max }=6.9$; and $\Delta \mathrm{m}_{1}=1$ (interval below the magnitude level $\mathrm{m}_{\mathrm{c}}$, required in the considered probabilistic model). A rock soil type is assumed for each portfolio's location with shear wave velocity in the first $30 \mathrm{~m}$ of soil Vs $30=800 \mathrm{~m} / \mathrm{s}$.

A 10000-year stochastic catalogue is considered; for each event, 500 realisations of the IMs are generated. This maximum time and the number of simulations is selected based on the current catastrophe risk modelling practice and correspond to a good balance in terms of statistical validity of the loss estimates and computational burden. As discussed, AvgSa is selected as the primary IM, and it is calculated in the period range [ $\left.\mathrm{T}_{2}: 2 \mathrm{~T}_{1}\right]$ for both case-study frames (consistently with [41]).

\section{RESULTS}

\subsection{Effects of ground-motion duration on hazard}

Ground-motion duration increases with the distance from the source due to the scattering and dispersion of seismic waves and the difference in the arrival times of waves propagating at different velocities and traversing different paths (e.g., [42]; [43]; [44]). However, duration also depends on local site conditions, with longer duration ground-motions typically observed at sites with softer soils due to repeated seismic wave reflections within the soft-soil layer and the respective dynamic amplification [45].

Figure 5a and Figure 5c show the obtained AvgSa and Ds5-95 hazard curves (individual simulations and median); while Figure 5b and Figure 5d show the AvgSa and Ds5-95 ground-motion fields (median), considering 2500-year mean return period (MRP) for one of the two index buildings (i.e., PB). As expected, the AvgSa values decrease, and the Ds5-95 values increase with distance. It is worth noting that the AvgSa ground-motion field varies for each of the index buildings (not shown here for brevity) since AvgSa is structure-dependent. At the same time, 
the Ds5-95 ground-motion field is the same for every index building. In the PB case, AvgSa ranges from around $0.05 \mathrm{~g}$ to $1.10 \mathrm{~g}$; the Ds5-95 ranges from approximately $20 \mathrm{~s}$ to $70 \mathrm{~s}$.

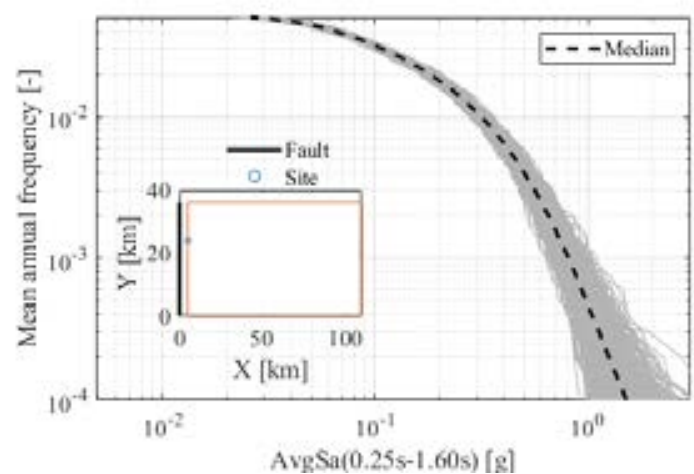

a) AvgSa hazard curve for a site

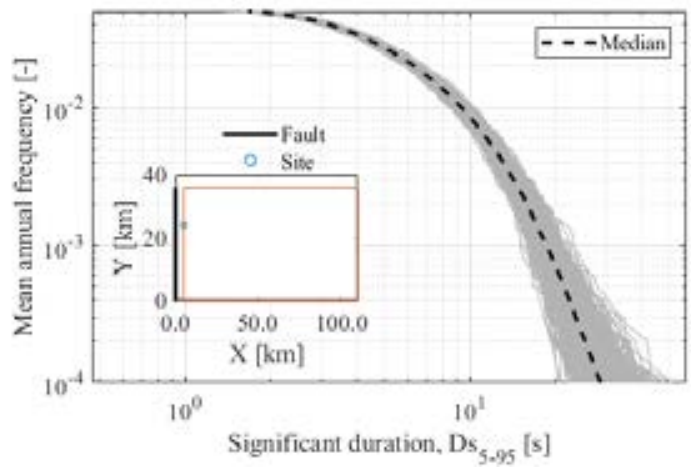

c) Ds5-95 hazard curve for a site

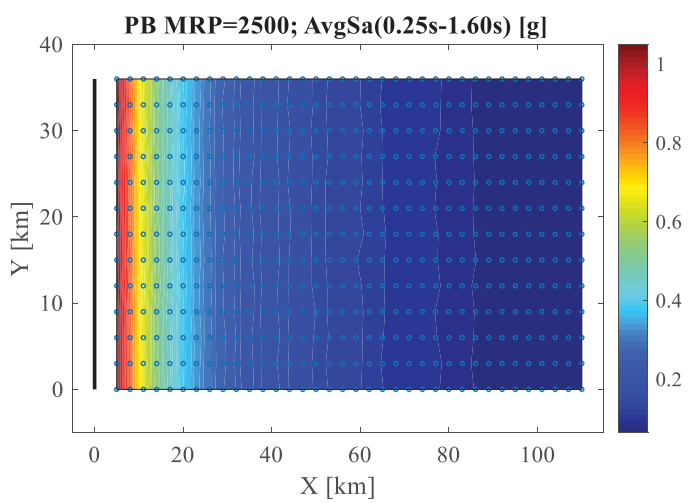

b) AvgSa ground-motion field $M R P=2500 ; D_{5-95}[s]$

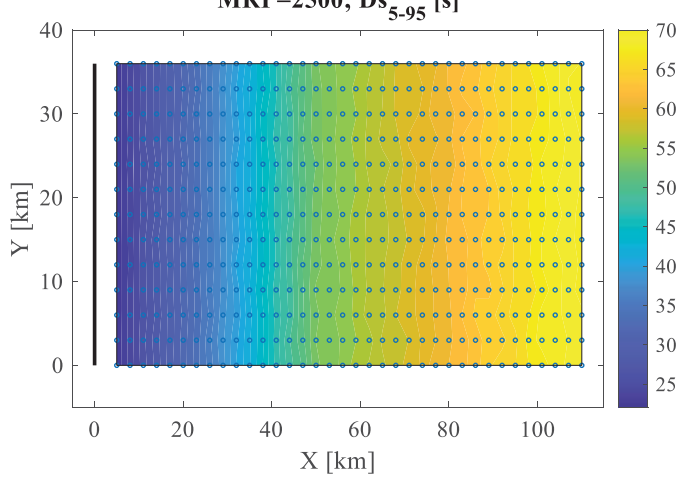

d) Ds5-95 ground-motion field

Figure 5: Simulation-based PSHA results for the region.

\subsection{Effects of ground-motion duration on vulnerability}

Figure $6 \mathrm{a}-\mathrm{b}$ show the fragility and vulnerability models obtained using AvgSa as an IM after performing the IDA for the PB frame. These relationships implicitly account for the significant duration since the structure hysteretic models can well capture the cyclic and in-cycle strength and stiffness deterioration (using the EH dissipated in each component) and the ratcheting of MIDR accentuated by the $P-\Delta$ effects. Similar behaviour is presented in different empirical damage models such as the Park and Ang damage index [46].

Figure 6c-d show the fragility and vulnerability models obtained using AvgSa and Ds5-95 in a vector-valued format after performing the IDA. The fragility and vulnerability surfaces explicitly account for the ground-motion duration since Ds5-95 can describe part of the variability of AvgSa, even if the latter is scaled during the nonlinear procedure. It could be noticed from the results that ground-motion duration mainly affects the higher DSs (i.e., DS3, DS4 and DS5), whilst the lower damage states (i.e., DS1 and DS2) remain approximately unaffected. This explained why the vulnerability surface exhibits a slight but steady increase in the loss ratio due to duration. On the other hand, the fragility relationship surface for DS5 exhibits a more significant (i.e., steeper) increase from short to long durations (i.e., from $1 \mathrm{~s}$ up to $60 \mathrm{~s}$ as depicted in the figure). In every case, the duration effects are consistently more apparent at lower durations and increase as AvgSa increases.

It is worth mentioning that the previous results are consistent among all the index buildings considered in this study. The fragility and vulnerability models are structure-dependent; therefore, these models vary accordingly per each case study (not shown here for brevity). 


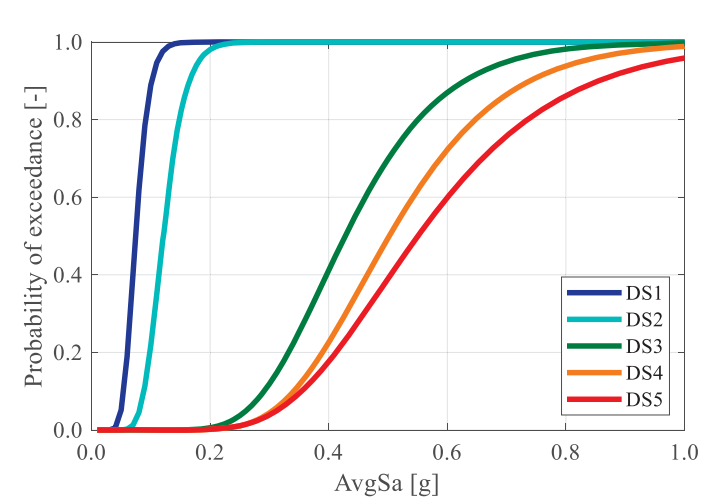

a) Fragility relationship

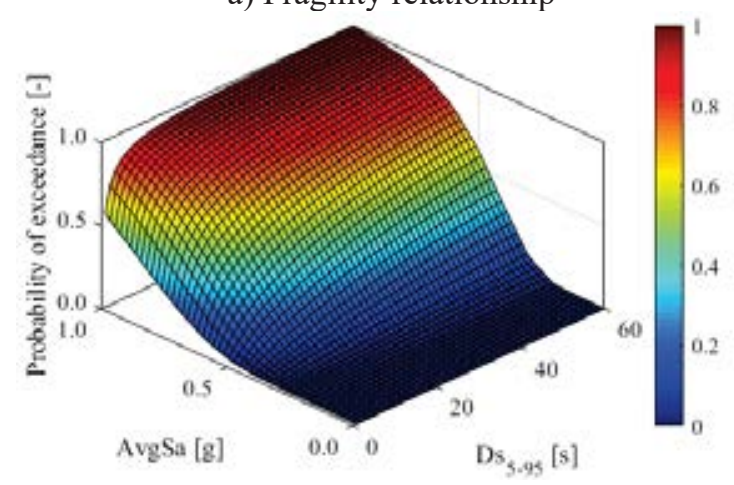

c) Fragility surface for DS5

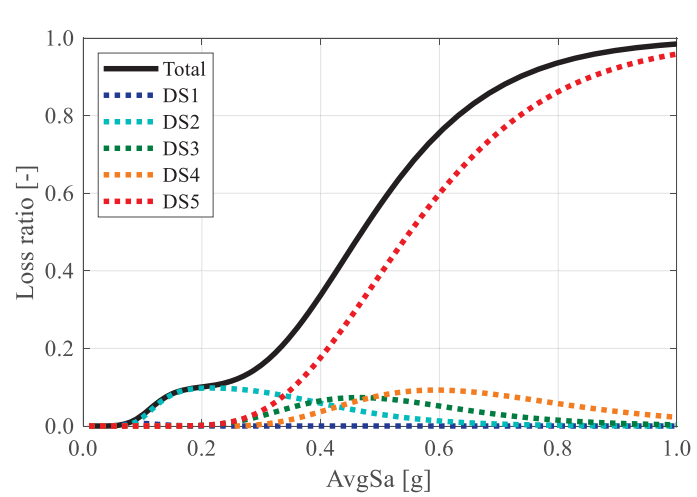

b) Vulnerability relationship

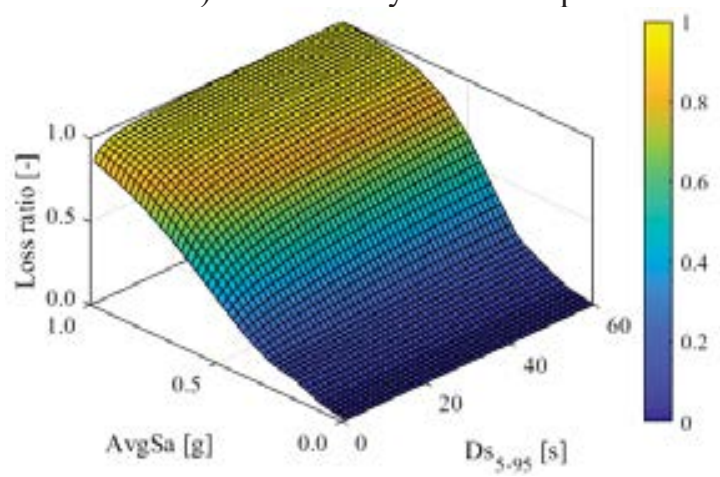

d) Vulnerability surface

Figure 6: Fragility and vulnerability models for PB frame.

\subsection{Effects of ground-motion duration on losses}

Figure 7a-b presents the median normalised loss ratio (NLR) corresponding to 2500 years MRP at each location within the region (i.e., normalised loss maps), computed as shown in equation 11. As expected, the NLR increases with distance when the IM explicitly accounts for duration (i.e., utilising the previously described vector-valued IM). The latter result is more apparent for the SB frame case, where the NLR can reach values around $60 \%$. It is important to note that losses decrease dramatically with distance, and low LR values are obtained for sites located far away from the source (e.g., at $100 \mathrm{~km}$ from the source). Therefore, small fluctuations in LR estimates at these locations can result in obtaining high NLR values. Thus, these high NLRs may not necessarily represent significant differences in the loss estimates from a practical point of view.

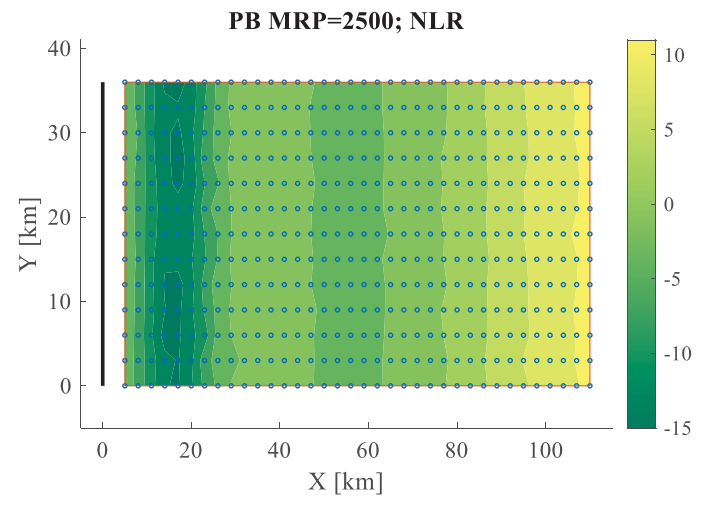

a) Normalised loss ratio (median) for PB frames

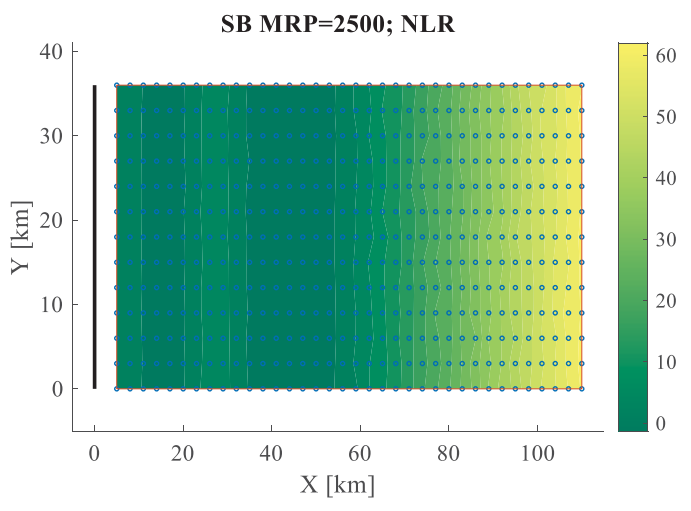

b) Normalised loss ratio (median) for SB frames

Figure 7: Normalised loss ratio (median) for PB and SB frames (MRP $=2500$ years) $[\%]$. 
It is worth noting that the results obtained for the SB frame are not consistent with the ones obtained when using the PB frame since, for locations relatively near the source (from $5 \mathrm{~km}$ to $25 \mathrm{~km}$ from the source), the NLR is higher when AvgSa is used as a scalar IM. This indicates that using duration in the vector-valued IM can increase or decrease the NLR value with respect to the scalar IM, given the region seismic hazard, exposure, and vulnerability models under consideration.

$$
\frac{\left[\mathrm{LR}\left(I M_{\text {vector }}\right)_{M R P=2500 \text { years }}-\mathrm{LR}\left(I M_{\text {scalar }}\right)_{M R P=2500 \text { years }}\right]}{\operatorname{LR}\left(I M_{\text {vector }}\right)_{M R P=2500 \text { years }}}
$$

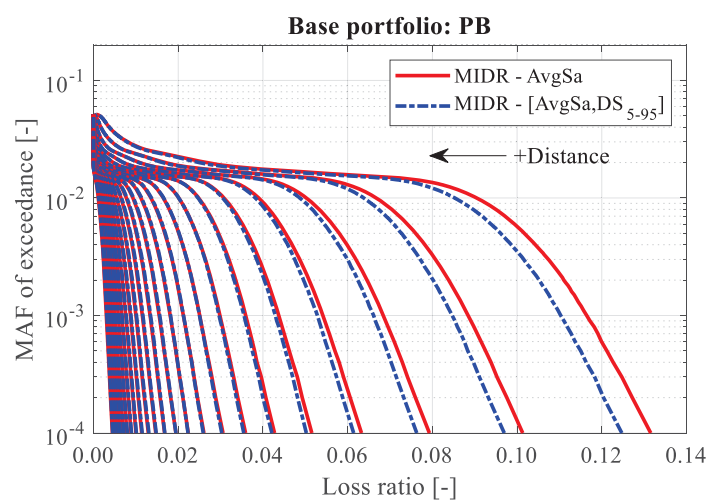

a) Aggregated loss curves (median) for PB portfolio

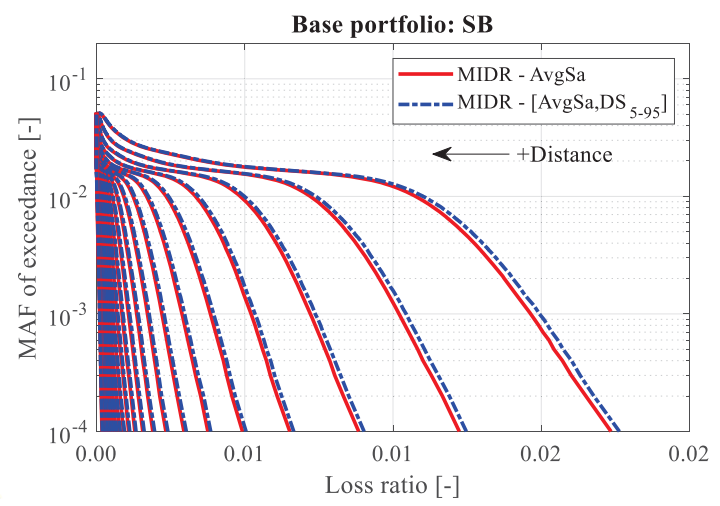

c) Aggregated loss curves (median) for SB portfolio

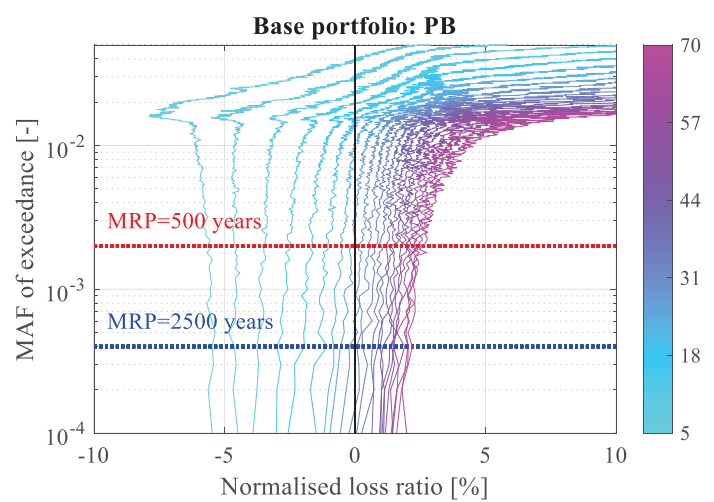

b) Aggregated normalised loss curves for PB portf.

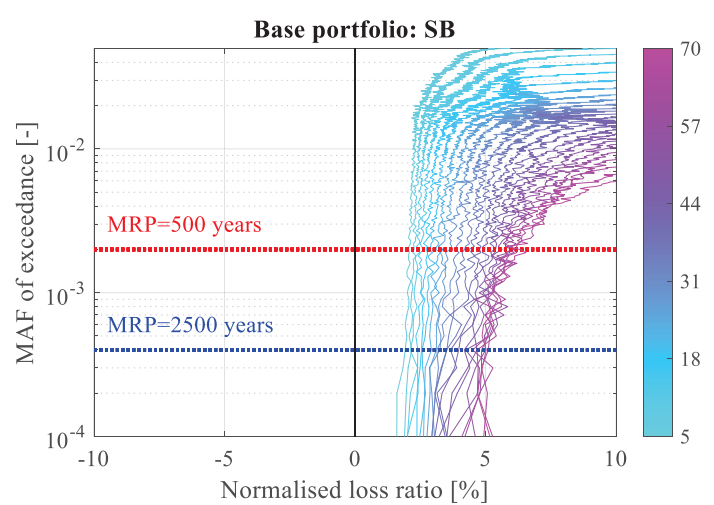

d) Aggregated normalised loss curves for SB portf.

Figure 8: Aggregated loss curves (median) pairs and aggregated normalised loss curves (median) variating with distance for PB and SB portfolios. The colour bar represents the distance from the source [km].

Figure 8a-d offers a better picture of how losses (i.e., LR or NLR as appropriate) and their mean annual frequency of exceedance (for different MRP) vary with distance. The left panels in these figures show the aggregated loss curves (median) for portfolios located at different distances from the source and using AvgSa or [AvgSa,Ds5-95] respectively (the distance increase from right to left as indicated). The right panel in these figures show the corresponding aggregated normalise loss curves (median) for selected portfolios (the aggregated normalise loss curves are estimated using equation 11 for every MRP associated with each mean annual frequency of exceedance, MAFE). The results are shown for two portfolios composed of PB (see Figure 8a-b) and SB (see Figure 8c-d) frames for the considered base portfolio size.

Regarding the portfolio made exclusively of PB buildings, when using AvgSa as an IM, the obtained LRs are higher in the vicinity of the source than those computed when using [AvgSa,Ds5-95] as an IM. Thereby, accounting explicitly (i.e., using the vector-valued IM) for duration near the source provides lower LR estimates. The previous behaviour varies with 
distance up to $25 \mathrm{~km}$ from the source approximately; in this case, the losses computed using [AvgSa,Ds5-95] as an IM are higher than those estimated using AvgSa as IM. The previous results are valid for MAFEs below roughly 1/100 years, as noticed in the figures. For relatively large MAFE value (above 1/100 years), the NLR are higher than 10\%, indicating that the vector-valued IM can better capture duration effects for moderate seismic events.

Interestingly for the portfolio made of SB buildings, when using AvgSa as an IM, the resulting LR results are lower than those obtained when [AvgSa,Ds5-95] is used as an IM. This may be due to the fact that a special-code frame (i.e., SB frame) with higher levels of strength and ductility can dissipate higher EH levels. Since significant duration is better correlated to structures behaving in such a way, its effect could be more apparent when duration is considering explicitly for intensity levels that are not causing structural collapse. In contrast, a pre-code building (i.e., PB frame) may collapse given the same intensity level without dissipating significant amounts of $\mathrm{EH}$ (as it occurs next to the source). These results reinforced the idea that the vector-valued-based vulnerability model can better capture duration effects given the considered seismic hazard, exposure, and vulnerability models.

The EAL is a suitable parameter to represent portfolio losses; therefore, the EAL is computed for all the possible distances within the region for the same portfolios analysed above. The outcome depends strongly on the portfolio composition when using both vulnerability models (i.e., scalar- and vector-valued-based vulnerability models). For the portfolio including only PB buildings, differences between the EAL values are at most 6\% (next to the source). In contrast, for the portfolio composed of SB buildings, EAL differences can reach up to $9 \%$ (far from the source). The noticeable trend among all distances is that, when EAL is used as a loss metric, there is a non-significant difference between using a scalar IM and a vector-valued IM accounting implicitly and explicitly for ground-motion duration, respectively.

\section{CONCLUSIONS}

This study investigated the influence of earthquake-induced ground-motion duration on estimating seismic losses for building portfolios using a simulation-based risk assessment framework. The aim was to examine how this ground-motion feature influences different loss estimates, investigating whether duration matters (depending on the location/portfolio) and should be included in the seismic risk assessment practice. The main conclusions of this work are summarised as follows:

- As expected, given the utilised GMMs, AvgSa intensity decrease and Ds5-95 increase with distance from the source;

- Duration can be implicitly or explicitly considered when fragility and vulnerability models are constructed. In general, the outcomes (i.e., loss estimates) do not match;

- Vector-valued fragility and vulnerability models may perform better in capturing the impact of ground-motion duration;

- The loss curves and EAL decrease rapidly with distance from the source; after $25 \mathrm{~km}-30$ $\mathrm{km}$, the differences when using a scalar and a vector-valued IM may be neglected;

- Building portfolio loss assessment is influenced by ground-motion duration, and its effect depends on the portfolio location and composition;

This study provided a first look at how to account for earthquake-induced ground-motion duration in building-portfolio loss estimation, and its results may not be generalised. Essential aspects such as the size of the portfolio, a realistic composition of the portfolio (e.g., mixed building typologies in the considered exposure), the use of more building typologies, complex source models, among others, were not considered in the paper but will be investigated in future developments of the study. 


\section{REFERENCES}

[1] V. Silva, H. Crowley, H. Varum, and R. Pinho, "Seismic risk assessment for mainland Portugal," Bull. Earthq. Eng., vol. 13, no. 2, 2015, doi: 10.1007/s10518-014-9630-0.

[2] R. Chandramohan, J. W. Baker, and G. G. Deierlein, "Quantifying the influence of ground motion duration on structural collapse capacity using spectrally equivalent records," Earthq. Spectra, vol. 32, no. 2, 2016, doi: 10.1193/122813EQS298MR2.

[3] J. Hancock and J. J. Bommer, "A state-of-knowledge review of the influence of strongmotion duration on structural damage," Earthquake Spectra, vol. 22, no. 3. 2006, doi: 10.1193/1.2220576.

[4] C. A. Cornell, "Does Duration Really Matter?," 1997.

[5] M. Raghunandan and A. B. Liel, "Effect of ground motion duration on earthquakeinduced structural collapse," Struct. Saf., vol. 41, 2013, doi: 10.1016/j.strusafe.2012.12.002.

[6] M. A. Bravo-Haro and A. Y. Elghazouli, "Influence of earthquake duration on the response of steel moment frames," Soil Dyn. Earthq. Eng., vol. 115, 2018, doi: 10.1016/j.soildyn.2018.08.027.

[7] K. Otárola-Madrigal, L. Sousa, R. Gentile, and C. Galasso, "Impact of earthquakeinduced ground-motion duration on nonlinear structural performance," MSc thesis, University of Pavia and University School of Advanced Studies (IUSS) Pavia, 2020.

[8] S. H. Hwang, S. Mangalathu, and J. S. Jeon, "Quantifying the effects of long-duration earthquake ground motions on the financial losses of steel moment resisting frame buildings of varying design risk category," Earthq. Eng. Struct. Dyn., 2020, doi: 10.1002/eqe. 3403 .

[9] D. Vamvatsikos and C. A. Cornell, "Applied incremental dynamic analysis," Earthq. Spectra, vol. 20, no. 2, 2004, doi: 10.1193/1.1737737.

[10] J. W. Baker, "Probabilistic structural response assessment using vector-valued intensity measures," Earthquake Engineering and Structural Dynamics, vol. 36, no. 13. 2007, doi: 10.1002/eqe. 700 .

[11] R. Gentile and C. Galasso, "Accounting for directivity-induced pulse-like ground motions in building portfolio loss assessment," Bull. Earthq. Eng., 2020, doi: 10.1007/s10518-020-00950-9.

[12] M. Pagani, D. Monelli, G. A. Weatherill, and J. Garcia, "The OpenQuake-engine Book: Hazard," GEM Found., 2014.

[13] D. L. Wells and K. J. Coppersmith, "New empirical relationships among magnitude, rupture length, rupture width, rupture area, and surface displacement," Bull. - Seismol. Soc. Am., vol. 84, no. 4, 1994.

[14] B. A. Bradley, "A ground motion selection algorithm based on the generalized conditional intensity measure approach," Soil Dyn. Earthq. Eng., vol. 40, 2012, doi: 10.1016/j.soildyn.2012.04.007.

[15] K. W. Campbell and Y. Bozorgnia, "NGA-West2 ground motion model for the average horizontal components of PGA, PGV, and 5\% damped linear acceleration response spectra," Earthq. Spectra, vol. 30, no. 3, 2014, doi: 10.1193/062913EQS175M.

[16] K. Afshari and J. P. Stewart, "Physically parameterized prediction equations for significant duration in active crustal regions," Earthq. Spectra, vol. 32, no. 4, 2016, doi: 10.1193/063015EQS106M.

[17] J. W. Baker and N. Jayaram, "Correlation of spectral acceleration values from NGA ground motion models," Earthq. Spectra, vol. 24, no. 1, 2008, doi: 10.1193/1.2857544.

[18] B. A. Bradley, "Correlation of significant duration with amplitude and cumulative 
intensity measures and its use in ground motion selection," J. Earthq. Eng., vol. 15, no. 6, 2011, doi: 10.1080/13632469.2011.557140.

[19] G. A. Weatherill, V. Silva, H. Crowley, and P. Bazzurro, "Exploring the impact of spatial correlations and uncertainties for portfolio analysis in probabilistic seismic loss estimation," Bull. Earthq. Eng., vol. 13, no. 4, 2015, doi: 10.1007/s10518-015-9730-5.

[20] L. F. Ibarra, R. A. Medina, and H. Krawinkler, "Hysteretic models that incorporate strength and stiffness deterioration," Earthq. Eng. Struct. Dyn., vol. 34, no. 12, 2005, doi: 10.1002/eqe.495.

[21] D. G. Lignos and H. Krawinkler, "Deterioration Modeling of Steel Components in Support of Collapse Prediction of Steel Moment Frames under Earthquake Loading," $J$. Struct. Eng., vol. 137, no. 11, 2011, doi: 10.1061/(asce)st.1943-541x.0000376.

[22] M. Rahnama and H. Krawinkler, "Effects of Soft Soil and Hysteresis Model on Seismic Demands," John A. Blume Earthq. Eng. Cent. Tech. Rep. Ser., vol. TR108, no. 108, 1993.

[23] K. Porter, R. Kennedy, and R. Bachman, "Creating fragility functions for performancebased earthquake engineering," Earthq. Spectra, vol. 23, no. 2, 2007, doi: 10.1193/1.2720892.

[24] T. Rossetto and A. Elnashai, "Derivation of vulnerability functions for European-type RC structures based on observational data," Eng. Struct., vol. 25, no. 10, 2003, doi: 10.1016/S0141-0296(03)00060-9.

[25] G. Di Pasquale, G. Orsini, and R. W. Romeo, "New developments in seismic risk assessment in Italy," Bull. Earthq. Eng., vol. 3, no. 1, 2005, doi: 10.1007/s10518-0050202-1.

[26] K. Mitchell-Wallace, M. Jones, J. Hillier, and M. Foote, Natural catastrophe risk management and modelling: A Practitioner's Guide. 2017.

[27] T. D. Ancheta et al., "PEER NGA-West2 Database," PEER Rep., no. May 2013, 2013.

[28] S. Minas and C. Galasso, "Accounting for spectral shape in simplified fragility analysis of case-study reinforced concrete frames," Soil Dyn. Earthq. Eng., vol. 119, 2019, doi: 10.1016/j.soildyn.2018.12.025.

[29] Eurocode 8, "European Standard EN 1998-3:2005: Design of structures for earthquake resistance - Part 3: Assessment and retrofitting of buildings," Com. Eur. Norm. Brussels, vol. 3, no. 2005, 2005.

[30] Consiglio dei ministri, "Regio Decreto Legge n. 2229 del 16/11/1939." G.U. n.92 del 18/04/1940, 1939.

[31] K. Aljawhari, R. Gentile, F. Freddi, and C. Galasso, "Effects of ground-motion sequences on fragility and vulnerability of case-study reinforced concrete frames," Bull. Earthq. Eng., 2020, doi: 10.1007/s10518-020-01006-8.

[32] G. M. Verderame, G. Manfredi, and G. Frunzio, "Le proprietà meccaniche dei calcestruzzi impiegati nelle strutture in cemento armato realizzate negli anni ' 60 ," $X$ Congr. Naz. "L'Ingegneria Sismica Ital. - ANIDIS, 2001.

[33] G. M. Verderame, P. Ricci, M. Esposito, and F. C. Sansiviero, "Le Caratteristiche Meccaniche degli Acciai Impiegati nelle Strutture in C.A. Realizzate dal 1950 al 1980," Aicap-Reluis, 2011.

[34] N. Mohammad Noh, L. Liberatore, F. Mollaioli, and S. Tesfamariam, "Modelling of masonry infilled RC frames subjected to cyclic loads: State of the art review and modelling with OpenSees," Eng. Struct., vol. 150, 2017, doi: 10.1016/j.engstruct.2017.07.002.

[35] S. Mazzoni, F. McKenna, and M. Scott, "Open system for earthquake engineering simulation (OpenSees)," Berkeley, Calif., 2006.

[36] F. Zareian and R. A. Medina, "A practical method for proper modeling of structural 
damping in inelastic plane structural systems," Comput. Struct., vol. 88, no. 1-2, pp. 4553, Jan. 2010, doi: 10.1016/j.compstruc.2009.08.001.

[37] T. B. Panagiotakos and M. N. Fardis, "Deformations of reinforced concrete members at yielding and ultimate," ACI Struct. J., vol. 98, no. 2, 2001, doi: 10.14359/10181.

[38] E. J. Setzler and H. Sezena, "Model for the lateral behavior of reinforced concrete columns including shear deformations," Earthq. Spectra, vol. 24, no. 2, 2008, doi: 10.1193/1.2932078.

[39] T. Rossetto et al., "FRACAS: A capacity spectrum approach for seismic fragility assessment including record-to-record variability," Eng. Struct., vol. 125, 2016, doi: 10.1016/j.engstruct.2016.06.043.

[40] V. Convertito, A. Emolo, and A. Zollo, "Seismic-hazard assessment for a characteristic earthquake scenario: An integrated probabilistic-deterministic method," Bull. Seismol. Soc. Am., vol. 96, no. 2, 2006, doi: 10.1785/0120050024.

[41] A. K. Kazantzi and D. Vamvatsikos, "Intensity measure selection for vulnerability studies of building classes," Earthq. Eng. Struct. Dyn., vol. 44, no. 15, 2015, doi: 10.1002/eqe.2603.

[42] M. D. Trifunac and A. G. Brady, "A study on the duration of strong earthquake ground motion," Bull. Seismol. Soc. Am., vol. 65, no. 3, 1978.

[43] S. Stein and M. Wysession, An Introduction to Seismology, Earthquakes, and Earth Structure. Oxford, UK: Blackwell Publishing Ltd., 2003.

[44] D. M. Boore and E. M. Thompson, "Path durations for use in the stochastic-method simulation of ground motions," Bull. Seismol. Soc. Am., vol. 104, no. 5, 2014, doi: $10.1785 / 0120140058$.

[45] R. Dobry, I. M. Idriss, and E. Ng, "Duration characteristics of horizontal components of strong-motion earthquake records," Bull. Seismol. Soc. Am., vol. 68, no. 5, 1978.

[46] Y. Park and A. H. -S. Ang, "Mechanistic Seismic Damage Model for Reinforced Concrete," J. Struct. Eng., vol. 111, no. 4, 1985, doi: 10.1061/(asce)07339445(1985)111:4(722). 